\title{
Complementing content of English courses for enhancing communication of IT-professionals for sustainable development
}

\author{
Svitlana Symonenko* \\ Dmytro Motornyi Tavria State Agrotechnological University, Department of Foreign Languages, Melitopol, 72312, Ukraine
}

\begin{abstract}
The paper deals with the issue of English language training for IT-specialists at Ukrainian universities. Understanding the importance of studying foreign languages has been confirmed by a number of normative documents. Peculiarities of professional training of IT-specialists at higher education institutions with the focus on foreign language training are considered. Pedagogical conditions for formation of communicative competence of IT-specialists are analysed. The content analysis of existing English language course books and textbooks for IT-specialists has been conducted to find out the content of foreign language training. It is stated that English language teaching aids in information technology, computer engineering, computing and software engineering can be used in the learning process, however, their use requires thorough refinement and modification. The series of guides and manuals for teaching English for professional purposes are presented.
\end{abstract}

\section{Introduction}

Education institutions have always been the space for implementation of new ideas, venues of progressive events and places for changes and new discoveries. It comes as no surprise universities around the world have become main promoters of sustainable development ideas and goals. Education for Sustainable Development (ESD) emphasizes the necessity of "equipping students with the knowledge and understanding, skills and attributes needed to work and live in a way that safeguards environmental, social and economic wellbeing, both in the present and for future generations" [1].

Modern realms prove that much more attention is given to environmental and economic spheres of life, while the socio-cultural area remains untouchable [2]. Languages, communication, human interaction are essential parts of human lives, and they cannot be disregarded in this respect. In addition, the question arises of why languages are missing from the Sustainable Development Goals (SDGs), as these are precisely languages that can deliver the SDGs correctly and accessibly. Moreover, " $99 \%$ of negotiations on the SDGs were done in English, and 100\% of negotiation outcomes were written in English" [3].

Nowadays. foreign language training is an integral component of all stages of secondary and higher education, and this process becomes even more significant under the conditions of ESD. The high level of the language proficiency, certainly, fosters career promotion, the increase of the intellectual and cultural levels of specialists, and easy adaptation of them in a foreign language environment. Employer requirements for engineering and technical knowledge, skills and competences are constantly being complicated. This happens due to the accelerated evolution of technical skills, the emergence of new engineering professions and the penetration of technology in all the areas of human lives. This fact also imposes an imprint on the foreign language level requirements. The significance of the sufficient foreign language level for IT-professionals is even more crucial, as they often work in international companies or teams, therefore the foreign language knowledge impacts on the result of their individual or joint work.

The objective of the paper is to carry out the analysis of existing course books and textbooks for IT-specialists in the context of their training at higher education institutions.

\section{Peculiarities of training for IT- specialists at higher education institutions}

The analysis of scientific publications has shown that peculiarities of professional training of IT-specialists have been studied by O. Dubinina [4], A. Striuk [5], M. Sydorov [6], L. Tereminko [2] et al. Researchers V. Kruhlyk [8], V. Osadchyi [9] have been engaged in the analysis of professional qualities of software engineers. Certain aspects of communicative training of IT-specialists have been investigated by H. Babii [10], Ya. Bulakhova [11], I. Chirva [12], O. Kirilenko [13], V. Strilets [14] and other researchers.

A. Striuk [5] notes that a software engineering specialist must be familiar with computer hardware,

* Corresponding author: asimonenko@ukr.net 
system infrastructure, methods, tools and technologies for developing software; be able to design, develop and maintain software. The scientist emphasizes that in the field of information technology big and small projects that require skilled management are implemented, and therefore students of the "Software Engineering" speciality learn to solve the problems of justification, planning, ensuring economic efficiency, quality and timely implementation of software projects working in teams. In the context of globalization, the development of software using the Internet is widespread, so students learn the appropriate technologies. The author focuses on soft skills of students majoring in software engineering, but he does not fully take into account the importance of foreign language training for IT-specialists.

L. Tereminko, studying problems of communicative competence improvement for competitive ITprofessionals emphasizes that they are largely related to the low adaptability of the education system and, as a result, university graduates to the dynamic changes in the IT-industry. Therefore, one of the requirements for vocational training is the formation of student readiness for professional mobility as an integrative quality of the individual, which is the ability to actualize their potential opportunities for adaptation to rapid changes in the professional sphere, formed on the basis of awareness of the need for the specified quality in their successful professional realization and their high level of the professional competence, their desire to develop professionally and to succeed [7]. The researcher notes that professional disciplines have a great potential for forming readiness for professional mobility, and this process can be successfully supplemented by such disciplines of other cycles as foreign languages, in particular, English for professional purposes, psychology of business communication, and ethics and aesthetics.

An important contribution to the theory of vocational training of future specialists in software engineering has been made by O. Dubinina, who has developed the job description for a specialist in the field of software engineering. She has divided qualities that ensure the success of such a professional into personal qualities, interests, aptitude and abilities. The researcher has identified the professional tasks that such a specialist should solve, according to the types of professional activity. In particular, she identified the following professional tasks in the process of analytical activities of software engineering professionals: collecting and analyzing customer requirements for software; formalization of the subject area of the software project by the results of the terms of reference and rapid examination; assisting the customer in evaluating and selecting software options; participation in preparation of the commercial offer to the customer, preparation of the presentation and approval of the package of contract documents. The tasks of designing activities are the following ones: participation in the design of software components to the extent sufficient to design them within the task; creation of software components (coding, debugging, unit and integration testing); performing measurements and refactoring code according to plan; participation in the integration of software components; development of test environment, creation of test scenarios; development and execution of sketch, technical and working project documentation [4].

The technological activity implies the ability to perform the following professional tasks: development and application of automated design, development, testing and maintenance of software; development and application of methods and tools of management of engineering activities and processes of software life cycle; use of standard control methods, evaluation and quality assurance of software; ensuring compliance of the developed software products and technical documentation with Ukrainian and international standards, specifications, departmental normative documents and standards of the enterprise; participation in the research related to the subject of professional activities in accordance with approved objectives and techniques. Production activities are the following: interaction with customers in the process of implementation of the software project; participation in software development processes; participation in the creation of technical documentation on the results of the works; participation in the preparation of technical documentation and established reporting in the approved forms; planning and organizing your own work; planning and coordination of software setup and maintenance work; drawing up a technical task for software development; organization of work of small teams of program project executors; participation in the feasibility study of program projects; commissioning of the software; preventive and corrective maintenance of the software product during operation; training and consulting of users on work with the software system [4]. However, the scientist has not emphasized that most of these professional tasks will be difficult to accomplish without having the rather developed communicative competence, including the foreign language communicative competence.

M. Sydorov, I. Mendzebrovskyi, and A. Orekhov on the example of the Professional Practice of Software Engineering discipline puts forward the following requirements for the organization of professional training of specialists in software engineering. First, students should be prepared to adapt to specific work that is as close as possible to their real work, and teachers must be practically and professionally trained (in terms of software development). Therefore, it is advisable to conduct training within a software development company; involve professional developers in teaching disciplines; to organize practical classes according to modern requirements. Second, students should integrate their own knowledge and skills and direct the results to software development, and teachers, using appropriate teaching materials, should simplify this integration [6]. In their study, the authors have not focused on communicative training for future software engineering professionals.

This deficiency of research in the national scientific thought has been eliminated by some pedagogical studies. In particular, the researcher O. Kirilenko, on the basis of the analysis of international requirements for software engineering teaching (Curriculum Guidelines 
for Undergraduate Degree Programs in Software Engineering ACM / IEEE), notes that the listed abilities include not only highly specialized engineering knowledge, skills and qualities, but and "skills in effective reasoning, ability to work in a multidisciplinary team, understanding of professional and ethical responsibility for making engineering decisions, ability to analyze and criticize decisions, people management skills and understanding of the importance of lifelong learning "[13].

H. Babii considers the proficiency in professional communication to be important for software engineers, because "it is necessary to involve the whole team of specialists for development of modern software, which requires knowledge of teamwork skills, knowledge of psychology fundamentals, group dynamics and communication, which is a guarantee of achievement of professionally significant results" [10]. The researcher identifies two groups of competences that she considers as the basis of the cognitive component of the readiness for professional communication of future software engineers: instrumental and specialized-professional competences. The first group, according to the researcher, includes the ability to write and communicate in the native language (the ability to use the language correctly depending on the scope and purpose of communication, to make business papers); knowledge of another language(s) (practical knowledge of a foreign language in terms of subjects due to professional needs); the use of oral language within the framework of domestic, social and political and professional subjects; the ability to translate general economic texts from a foreign language into a native language); research skills (ability to apply research skills in specialized disciplines); the ability to create technical documentation for a software project. The second group includes the ability to conduct business negotiations with business partners and the ability to reasonably convince colleagues of the correctness of the proposed solution, the ability to convey to others their position [10].

I. Chirva believes that in today's realities there is a growing need for future software engineers to develop the skills and abilities of dialogic speech itself, which is conditioned by economic reforms being carried out in Ukraine at the present stage (contacts of specialists of technical profile with foreign partners when creating joint ventures, work with imported equipment, etc.). The scientist assures that students must be able to communicate effectively in English. According to the requirements of the English for Specific Purposes (ESP) program, a prospective professional should be able to respond to basic ideas and identify relevant important information during detailed discussions, discussions, formal talks, lectures, related conversations with training and profession. The high level of foreign language communicative competence of future software engineers is a guarantee of improvement of their professional level, enrichment of knowledge in a speciality and successful professional activity [12].

According to the Ya. Bulakhova, in their professional activity software engineers "must actively cooperate with foreign partners, representatives of different cultures and levels of professional competence; be aware of the latest scientific and technological developments in their manufacturing field, using foreign sources of information. The success of their professional activity depends on communication skills and knowledge of a foreign language". On this basis, the author insists that for the effective mastery of a foreign language, the following requirements must be taken into account: the orientation of the teaching system to the formation of students' systemic vision of the subjects studied; flexibility and variability of content, taking into account the needs of education and the individual; humanization of technical education; orientation on mastering new information technologies; ensuring the methodological, specialized scientific and professional competence of the specialist. While studying, students should be aware of the substantive and procedural part of their future professional activity [11].

The same opinion is emphasized by V. Strilets, pointing out that modern society needs specialists in programming who have the system thinking, are able to generate ideas, be aware of the responsibility for the consequences of the decisions made, quickly adapt to new conditions, find ways to overcome problem situations; are able to navigate the information space, quickly find and process the necessary information, use electronic communications, a variety of software when solving production tasks. In the professional field, software engineers mainly use foreign language when searching for and processing information from Internet resources, programming, and communicating with foreign partners through electronic communications [14]. Therefore, the process of foreign language training of future specialists in software engineering is important. The author highlights the following communicative skills of future programmers: reading in various modes (search, study, study) computer messages, system help programs, specifications, instructions, articles of electronic professional publications, materials of professional community forums, online workshops; participation in dialogue / discussion-dialogue, communicating both directly and through electronic means; production of a monologue presentation; writing instructions, reports, forum posts. Their formation is proposed to be implemented in the process of the project methodology of teaching English to future programmers using a distance course.

A high level of foreign language communication competence in the professional activity and professional environment is considered to be a necessary component of the characteristic of a modern IT-specialist. According to the research of I. Viakh, an IT specialist is considered competent if he or she successfully completes the following tasks in a foreign language: 1) finds the necessary information in a foreign language text without assistance; 2) understands technical instructions, articles, educational texts in foreign language from popular and promising areas of the IT industry without assistance; 3 ) uses tools that accelerate and refine the comprehension of a foreign language text (various electronic dictionaries, glossaries); 4) constantly improving foreign language skills; 5) makes a structured 
written presentation in a foreign language; 6) conducts competent correspondence in a foreign language with the customer, employer through messenger programs, email; 7) states the facts in a foreign language clearly, clearly orally and in writing; 8) competently and objectively verbally presents in a foreign language himself, his skills, experience, goals, aspirations; 9) draws up an effective competent resume in a foreign language, is able to sell his skills; 10) makes oral presentation in a foreign language; 11) formulates and communicates its ideas, proposes both verbally and in writing in a foreign language; 12) provides technical guidance in a foreign language, both orally and in writing; 13) advises clients and colleagues in a foreign language; 14) explains information to different audiences in a foreign language; 15) clarifies information for itself in a foreign language; 16) effectively agrees with the customer in a foreign language on: a) the subject area; b) product requirements; c) payment; d) terms; e) support; 17) distinguishes the main from the heard broadcast in a foreign language; 18) understands oral language directly, via telephone or messenger programs; 19) understands and takes into account the concept of time in different countries; 20) knows domestic and international business etiquette; 21) possesses socio-cultural knowledge of other countries (holidays, weekends, greetings, taboo topics, etc.) and takes them into account when communicating; 22) is engaged in professional selfeducation, reading professional literature, blogs, forums in a foreign language; 23) participates in the project, project planning, project management and evaluation of the project using a foreign language [15]. Thus, the researcher concludes that foreign language communication competence is a decisive factor in employment and career development in the IT field.

\section{Pedagogical conditions for the formation of communicative competence of IT-specialists}

The conditions under which communicative competence of modern professionals is formed have been investigated by O. Kraievska [16], I. Novgorodtseva [17], O. Yefimova [18], Z. Yermakova [19], in particular, communicative competence formation of future IT specialists has been studied by Ya. Bulakhova [11], I. Viakh [15], V. Chirva [12] and others.

O. Yefimova [18] defines the following pedagogical conditions, the observance of which ensures that students achieve a higher level of communication competence formation: 1) development of teacher empathy; 2) development of communication skills; 3) individualization of training (introduction of academic counseling (tutoring)) [11].

O. Kraievska [16] among the pedagogical conditions for the development of communicative competence of future agrarian managers places the need for the gradual formation of motivation for the communicative activity in the process of professional training of future agrarian managers. The other pedagogical condition is the development of the content of communicative training of future agrarian managers on the basis of systematic and integrative approaches. The implementation of these conditions is the basis for applying the methodology of complex formation of structural components of communicative competence using information and communication technology, which is advanced by the researcher as the third pedagogical condition.

I. Novgorodtseva determines that the formation of the professional communicative competence of future engineers at higher education institutions will be effective under the following organizational and pedagogical conditions: 1) orientation of professional training to the professional-communication competence of future engineers; 2) development of the author's training courses aimed at the formation of the professional and communicative competence; 3) development and use of the algorithm of formation of the professional communicative competence of future engineers, containing three interrelated stages: preparatory (knowledge), basic (activity), and final (reflective) ones; 4) use of pedagogical technologies, a complex of didactic means in the process of professional training of future engineers; 5) development of a system of criteria for assessing the levels of the professional communicative competence of a fut7re engineer [13].

I. Viakh has identified the following conditions for the formation of foreign-language communicative competence of future specialists in the field of information technology: systematic learning the industry-specific content in a foreign language, modeling the professional activities of future specialists in the field of information technology by means of a foreign language, implementation of the principles of mixed learning materials in teaching materials [15]. The researcher has paid particular attention to the use of information and communication technologies in the process of forming foreign communication skills of future specialists in the field of information technologies, namely applying instant messaging programs Skype, Google Talk, ICQ, QIP, Miranda, professional electronic journals (Tech Crunch, Computer, EEEM), blogs (A + Computer Science Blog, Pastacode computer science blog, etc.) and country sites.

Exploring the methodological approaches to teaching English dialogues of future software engineers, I. Chirva [12] believes that creating a favorable environment with the use of level differentiation is important for mastering each student according to the level of their academic achievements and abilities. In her opinion, it is advisable to introduce a computer program for the organization of differentiated teaching of English dialogues of future software engineers in a technical institution of higher education, which is justified by the need to improve the quality of foreign language training of future software engineers at all levels; the need to obtain the desired result is to increase students' skills and competences. Instead, the researcher Ya. Bulakhova identifies meaningful and procedural pedagogical conditions for teaching software engineers, which take into account the connection between social contract for engineering training, contradictions at national higher education 
institutions and the specifics of teaching a foreign language at a university [11].

Based on the research of $\mathrm{Z}$. Yermakova, we follow this understanding of the pedagogical condition: a circumstance on which the performance of professional activity depends and in which different results are possible [19].

The analysis of modern requirements for the organization of professional training of software engineers in Ukraine and abroad, the generalization of the experience of forming communicative competence of IT-specialists allow us to distinguish the following organizational and pedagogical conditions for the formation of communicative competence of software engineering specialists at institutions of higher education [20]:

1. Complementation of the content of curricula and educational-methodological complexes of foreign language disciplines with exercises, activities, texts and patterns of effective professional communication.

2. Application of interactive forms of training of selected professional disciplines, taking into account the specifics of professional activities of software engineers in the implementation of dominant methods (project method, method of teaching in collaboration (small groups), "brainstorming", case method).

3. Use of synchronous and asynchronous communication tools, special Internet resources, social online networks and virtual communities in the teaching of foreign language and vocational disciplines in foreign language in classroom and extra-curricular work.

The efficiency of the process of forming techniques and methods of interpersonal interaction, which form the basis of professional communication of software engineers is ensured by involving students in communication activities, which maximally simulates the process of professional interaction and creates the conditions for professionally and personally-oriented professionals.

\section{Content analysis of course books and textbooks for teaching English for IT- specialists}

In order to complement the content of curricula and educational and methodological complexes of foreign language disciplines with exercises, activities, texts and patterns of effective professional communication we have analyzed the contents of course books and textbooks for teaching English at higher education institutions, and in particular for specialists in computer science, information technology, Internet technology and software engineering. The similar research has been carried out by Japanese educators J. Jodoin and J. Singer to analyze the contents of English textbooks to find out whether this material is used effectively to train university students in terms of SDG [21].

In our research the following aspects have been emphasized: the professional orientation of the content, the presence of exercises, tasks, job-related situations and activities for the development of all four language skills; the availability of additional materials, applications and resources for self-study.

The English Language Guide for PC Users and Programmers [22] provides educational materials for teaching English to technical students and students studying the English language, computer science and advanced computer technology. Each of the 25 lessons has two sections: Grammar and Vocabulary and Reading. The first section contains materials for learning English grammar in the traditional format. The second section contains a list of words for one or more texts and general exercises for vocabulary training on the main topics of computer science and programming. The benefits of the manual are its original structure and the use of basic special vocabulary, but the disadvantages are the moral obsolescence of the texts, the absence of listening activities and the lack of focus on developing communication skills, including the lack of dialogue practicing and job-related phrases.

The English for Internet Technology Professionals guide [23] is aimed at developing and developing language skills and skills in the language use in the field of professional communication. It contains authentic texts, tasks for listening and speaking, and vocabulary on seven topics: history of the Internet, Internet privacy, Internet services, online payment systems, E-mail service, personal web page, Internet security. The benefits of this guide include the availability of exercises and tasks for practicing communication skills (discussions, dialogues, reflections), but the vocabulary is limited to only one field - Internet technologies, which will not obviously be enough for IT-specialists to communicate.

Oxford English for Information Technology course book is intended for students majoring in information technology and computer engineering, for professionals already working in the field and who wish to improve and expand their English language skills in the context of information and communication technologies. Compared to the first edition of 2002 [24], the 2006 edition [25] takes into account the latest developments in this fast-growing sector, as reflected in the content update. New materials reflect changes in areas such as specifications, new technologies and practices. The student's book consists of 25 lessons covering a wide range of IT topics. The materials of the course book include authentic texts and visuals taken from textbooks, newspapers, popular computer magazines, online newsgroups, webpages, manuals and advertisements. Each lesson contains tasks for language skills development, and every fifth lesson focuses on developing listening skills through authentic interviews with IT professionals. For students who already have rather good knowledge of English vocabulary in IT, there are additional special reading texts. The teacher's guide includes a theoretical introduction to the topic of each lesson for non-IT teachers to better achieve the learning goals. However, the manual does not sufficiently focus on software development issues, communication with the team members and customers, which is an important topic for training software engineering professionals. 
The organization and drawbacks of the Professional English in Use: ICT manual [26] and English for Information Technology. Vocational English [27] are similar. The first covers a wide range of topics in information technology, including word processing, financial software and databases, multimedia applications, e-mail, web design and Internet security. Easy to use and clearly written, designed as a reference and practical manual for independent work, it can also be used as a supplement to classroom work only to improve the vocabulary of future software engineering professionals. The second book is intended for ITstudents and company employees and includes topics in current IT development, it has clear learning goals, online teacher support, CD-ROMs with audio files and interactive glossaries in US English and British English for students.

The English for Computer Science Students textbook [28] is offered for the analytical or home reading of vocationally-oriented texts, vocabulary boosting, English-speaking skills in oral and written forms. It consists of 9 lessons, each of which in addition to the industry-specific texts contains a number of interesting exercises aimed at mastering scientific and technical vocabulary, namely terms, abbreviations, acronyms, etc. The guide is aimed at students, graduate students and anyone with a basic knowledge of English and interested in current issues related to the emergence, development and future of computers in the global computerization of society.

Among the analyzed publications the Express Publishing editions of Career Paths series are of special interest. The series is intended for professionals who want to improve their English language skills in the work environment. They include a special vocabulary and texts, step-by-step tutorials that immerse learners into four major language aspects: reading, listening, speaking and writing. The course book contains three books in three difficulty levels (A1, A2 and B1) and offers over 400 lexical terms and phrases. Each lesson includes a test to check reading comprehension, vocabulary and listening skills, and help students develop their writing and oral communication skills. The Career Paths: Information Technology Guide [29] covers topics related to computer design: components, hardware, software, Internet security, web design, and the future of the IT industry. The Career Paths: Computing Guide [30] is intended for professionals who want to improve their English communication skills in the computer industry. It includes topics related to computer hardware, general applications, operating systems, online communications, and cloud computing.

The Career Paths: Software Engineering Guide [31] discusses topics in software development, software testing, user interface, modeling, and career options in software engineering. An important structural element of this publication is dialogues specific to the profession and the numerous job-related texts in the field of software engineering. Therefore, this guide combines specialized vocabulary and professional context to form necessary communication skills for a career. The textbook contains three books of different levels:
Elementary (Book 1), Pre-intermediate (Book 2), and Intermediate (Book 3). The books contain 15 lessons of different topics, each topic focuses on a specific reading context and serves to form a certain communicative skill. For example, the second lesson on Types of Computers contains the text for reading in the form of a magazine article, which involves new vocabulary acquisition (computer, computing cluster, desktop, embedded computer, laptop, notebook, PC, server, tablet, workstation) and aimed at forming ability to make plans. However, despite the elaborate structure, professionally oriented exercises, texts and dialogues, the disadvantage of the course book is that there is no consistency between the topic of the lesson, the vocabulary words to learn and the skills formed during the lesson.

The content analysis of course books and textbooks for English learning at higher education institutions, in particular, for professionals in the field of information technology and software engineering, has shown the abstract nature of the used case studies and low applied importance of the chosen topics of educational interaction. Therefore, as a result of the analysis of English language teaching aids in information technology, computer engineering, computing and software engineering, we can conclude that some of them can be used in the learning process, however, their use requires thorough refinement and modification.

In order to improve the content of English language learning to form communicative competence of software engineering specialists at higher education institutions, taking into account all the advantages and disadvantages of existing teaching aids we have developed and implemented the following items:

1. The Improve Your Listening and Speaking for Future Software Engineering Professionals guide.

2. The Business English Essentials for Software Engineers manual.

3. The Dictionary of Acronyms and Abbreviations for Information Technology and Software Engineering Specialists.

4. Methodological Recommendations for the Formation of Communicative Competence of Future Specialists in Software Engineering.

5. Distant courses for studying English, English for Special Purposes and Business English.

The Improve Your Listening and Speaking Guide is intended for students of IT-specialities. It is aimed at teaching listening for better comprehending foreign language information, understanding general information, finding out the main ideas, extracting certain details or facts, and predicting key information before listening. The guide includes 24 sections covering a wide range of information technology issues: computer history, modern computers and their use in society, the Internet, global communications, wireless technology, computer games, digital libraries, software interfaces, graphical interface, software and others. The texts are selected from original modern sources, taking into account the latest trends in information technology and interests of modern students. The guide contains numerous diagrams, charts and illustrations that facilitate 
the perception of information and tasks. The manual includes audio files with scripts.

Each section contains a list of specific terms, listening tasks, and professional texts. The activities cover a number of questions that require not only specialized but also personal general knowledge regarding IT problems. Listening tasks vary in their form: answering questions, writing down terms, selecting facts in a report, filling in a chart or table using facts from a report, filling gaps, etc. After-listening activities typically involve discussion questions that develop speaking skills in the professional software engineering environment.

The Business English Essentials for Software Engineers guide is intended for senior students of ITspecialities. It should be noted that the manual is designed to deepen the students' language skills in reading and speaking, improve their writing skills, as well as develop their ability to process original and prepare their own documents in English. The guide consists of 10 units covering the main types of business oral and written communication in software engineering. At the beginning of each block the list of active vocabulary is given. Post-text exercises are aimed at productive and reproductive activities. To simplify the processing of authentic and didactic materials, the guide contains a large number of samples of English-language documents in software engineering and information technology in general, intended for both classroom use and self-study. The information is retrieved and adapted from modern online materials and resources.

The Glossary of Software Engineering Acronyms and Abbreviations contains 12,000 terms and is intended for students who study IT and it is also useful for teachers of professional disciplines who train future ITspecialists.

Methodological Recommendations for the Formation of Communicative Competence of Future Specialists in Software Engineering provide student advice for oral and written communication in the work environment and in the software development process. The manual is intended for students who are interested in software engineering as a field of information technology, which deals with the application of a systematic approach to the development, use and maintenance of software, and the study of these approaches, i.e. the application of engineering principles to software. The manual also features an English-Ukrainian phrasebook for software engineering professionals.

The guide contains 12 topics that address situations, problems, and tasks that arise during professional activities in software development. Tips on writing business letters and cover letters, talking on the phone, writing a resume, looking for a job, holding a teleconference, presentation or meeting using professional English vocabulary and word-specific words are provided. Useful phrases for communicating with clients and colleagues are also given. Each topic presents language patterns of business professional communication in the field of software engineering.

The materials of the manual are presented in the form of communication patterns, which are easily perceived by students in the learning process, because they have a standard structure and are used in typical professional situations. Having studied the language patterns, presented in both English and Ukrainian, grouped in the manual according to professional situations, students will quickly be able to recall them in real-world professional activities and demonstrate the high level of communicative competence.

Combining disparate means of communication and purposeful influence on the formation of communicative competence is enabled by distance learning technologies. In order to support student self-study, distance learning courses for studying English, English for Special Purposes and Business English on the Moodle platform have been developed. The courses contain basic theoretical materials as well as additional materials: theoretical explanation of grammatical phenomena in the native language, audio and video materials with relevant tasks for understanding comprehension, conversational topics with tasks and comprehension check, texts for extra-curricular reading with tasks. The topics of the course are in strict accordance with the curriculum of the discipline. The students' progress in the course has been checked after each topic.

In order to facilitate communication in a foreign language, a chat has been created in the distant courses to ask questions, leave comments, answer questions, and share useful information.

\section{Conclusions}

Our research has made it possible to identify the progressive ideas of modern pedagogical science and to develop recommendations for improving the formation of communicative competence of IT-specialists at higher education institutions. Vocational training of ITspecialists in the $21^{\text {st }}$ century should involve significant intensification of language training, whereby synergies should be achieved through a set of training measures of active professional and linguistic training within separate practical courses; foreign language training should have the real-life flexible and variable context, taking into account the field of knowledge, its current state and sustainable development strategies and ideas. In the vocational training of IT-professionals coherent problem modules with elements of private, business, academic professional and scientific communication in both oral and written formats should be implemented. It is necessary to emphasize that foreign language teachers need to modify the content, forms and methods of teaching foreign languages according to ESD to meet the requirements of professional communities in order to ensure the proper level of English command.

\section{References}

1. Quality Assurance Agency / Higher Education Academy, Education for sustainable development: guidance for UK higher education providers (2014), http://www.qaa.ac.uk/en/Publications/Documents/E 
ducation-sustainable-development-Guidance-June14.pdf. Accessed 05 Feb 2020

2. T. Zygmunt, Language Education for Sustainable Development. Discourse and Communication for Sustainable Education 7(1), 112-124 (2016). doi:10.1515/dcse-2016-0008

3. W. Tesseur, Why are languages missing from the Sustainable Development Goals? (2017), https://research.reading.ac.uk/research-blog/whyare-languages-missing-from-the-sustainabledevelopment-goals/. Accessed 05 Feb 2020

4. O. Dubinina, Dissertation, Kharkiv National Pedagogical University, 2016

5. S. Semerikov, A. Striuk, L. Striuk, M. Striuk, H. Shalatska, Sustainability in Software Engineering Education: a case of general professional competencies. E3S Web of Conferences (2020 in press)

6. M. Sydorov, I. Mendzebrovskyi, A. Orekhov, Software Engineering 2, 56-62 (2010)

7. L. Tereminko, Formation of readiness for professional mobility as an urgent professional training problem of future software engineers. Bulletin of National Aviation University 10, 139145 (2017). doi:10.18372/2411-264X.10.12521

8. V. Kruhlyk, V. Osadchyi, Developing competency in programming among future software engineers. Integration of Education 23(4), 587-606 (2019). doi:10.15507/1991-9468.097.023.201904.587-606

9. H. Chemerys, V. Osadchyi, K. Osadcha, V. Kruhlyk, CEUR Workshop Proceedings 2393, 1728 (2019)

10. H. Babii, Higher education of Ukraine 1, 162-170 (2012)

11. Ya. Bulakhova, Dissertation, Luhansk National Pedagogical University named after Taras Shevchenko, 2007

12. I. Chirva, Dissertation, Kyiv National Linguistic University, 2008

13. O. Kirilenko, Young researcher 3, 388-393 (2016)

14. V. Strilets, Dissertation, Kyiv National Linguistic University, 2010.

15. I. Viakh, Dissertation, Vinnytsya State Pedagogical University after Mykhailo Kotsyubynskyi, 2013

16. O. Kraievska, Scientific notes of the Ternopil National Pedagogical University named after Volodymyr Hnatyuk. Series: Pedagogy 3, 13-18 (2014)

17. I. Novgorodtseva, Dissertation, Volga State Engineering and Pedagogical University, 2008

18. O. Yefimova, Dissertation, National Pedagogical Dragomanov University, 2014

19. Z. Yermakova, Dissertation, Alfred Nobel University, 2015

20. S. Symonenko, Dissertation, Classical Private University, 2019
21. J. Jodoin, J. Singer, Mainstreaming Education for Sustainable Development in English as a Foreign Language: An Analysis of the Image-Text Interplay Found in EFL Textbooks in Japanese Higher Education, in Universities as Living Labs for Sustainable Development, ed. by Leal Filho W. et al. World Sustainability Series (Springer, Cham, 2020), pp. 545-565. doi:10.1007/978-3-030-15604-6_34

22. Ye. Goltsova, English Language Guide for PC Users and Programmers (Korona print, Saint Petersburg, 2002)

23. V. Vichugov, T. Krasnova, English for Internet Technology Professionals (Tomsk Polytechnic University, Tomsk, 2012)

24. E. Glendinning, J. MacEwan, Oxford English for information technology (Oxford University Press, Oxford, 2003)

25. E. Glendinning, J. MacEwan, Oxford English for information technology (Oxford University Press, Oxford, 2006)

26. E. Marco Fabré, S. Remacha Esteras, Professional English in use: ICT (Cambridge University Press, Cambridge, 2016)

27. D. Hill, English For Information Technology (Pearson Longman, Harlow, 2012)

28. T. Smirnova, M. Yudelson, English For Computer Science Students (Flinta, Moscow, 2017)

29. V. Evans, J. Dooley, S. Wright, Career Paths: Information Technology (Express Publishing, Newbury, 2011)

30. V. Evans, J. Dooley, W. Kennedy. Career Paths: Computing (Express Publishing, Newbury, 2011)

31. V. Evans, J. Dooley, E. Pontelli, Career Paths: Software Engineering (Express Publishing, Newbury, 2011) 